\title{
Current methodological approaches in conditioned pain modulation assessment in pediatrics
}

REVIEW

This article was published in the following Dove Press journal: Journal of Pain Research

\author{
Philippe S Hwang' \\ My-Linh $\mathrm{Ma}^{\mathrm{l}-3}$ \\ Nora Spiegelberg' \\ Catherine E Ferland ${ }^{1-5}$ \\ 'Shriners Hospital for Children - \\ Canada, ${ }^{2}$ Research Institute - \\ McGill University Health Centre, \\ ${ }^{3}$ Department of Experimental Surgery, \\ ${ }^{4}$ Department of Anesthesia, McGill \\ University, ${ }^{5}$ The Alan Edwards Centre \\ for Research on Pain, Montreal, QC, \\ Canada
}

\begin{abstract}
Conditioned pain modulation (CPM) paradigms have been used in various studies with healthy and non-healthy adult populations in an attempt to elucidate the mechanisms of pain processing. However, only a few studies so far have applied CPM in pediatric populations. Studies finding associations with chronic pain conditions suggest that deficiencies in underlying descending pain pathways may play an important role in the development and persistence of pain early in life. Twelve studies were identified using a PubMed search which examine solely pediatric populations, and these are reviewed with regard to demographics studied, methodological approaches, and conclusions reached. This review aimed to provide both clinicians and researchers with a brief overview of the current state of research regarding the use of CPM in children and adolescents, both healthy and clinical patients. The implications of CPM in experimental and clinical settings and its potential to aid in refining considerations to individualize treatment of pediatric pain syndromes will be discussed.
\end{abstract}

Keywords: conditioned pain modulation, descending endogenous pain inhibition, chronic pain, pediatrics

\section{Introduction}

In 1979, Daniel Le Bars, a French neurophysiologist proposed the term "diffuse noxious inhibitory controls" (DNIC) describing a reduced pain response occurring in converged dorsal horn neurons in rats after the application of nociceptive stimuli remote from a peripheral excitatory receptive field. ${ }^{1}$ Le Bars' observation of the inhibitory effect of pain, also known as "pain inhibits pain," has led to the development of experimental paradigms that intend to assess the endogenous analgesia capacity in healthy individuals and pain patients. ${ }^{2}$ Because these paradigms include a so-called conditioning stimulus (CS), which in turn modulates another pain-inducing stimulus (called the test stimulus [TS]), the paradigm is also referred to as conditioned pain modulation (CPM). ${ }^{3}$ The degree to which the perceived painfulness of the TS changes in response to the CS is thought to vary between individuals reflecting an underlying descending endogenous pain inhibition capacity. This analgesic capacity can be described on a clinical continuum ranging from pain facilitation to pain inhibition, and an individual can be positioned on this range accordingly. ${ }^{2}$ Although healthy individuals are thought to successfully inhibit pain exhibiting an efficient CPM, patients suffering from chronic pain conditions have demonstrated significantly lower CPM efficiency indicating deficient central pain processing. ${ }^{3}$ These effects have been intensively studied in adult populations leading to suggestions for more individualized mechanism-oriented pharmacological ${ }^{2}$
Correspondence: Catherine E Ferland Shriners Hospital for Children - Canada, 1003, Decarie Boulevard, Montreal, QC, Canada, H4A 0A9

Tel + I 5I4842 4464 ext 7I77

Email catherine.ferland@mcgill.ca 
or psychological intervention strategies. ${ }^{4}$ These findings in adult studies however cannot be extrapolated to pediatric populations without taking into account major differences in developmental and interpersonal characteristics. ${ }^{5}$ Tsao et al have found a significant variance in CPM exhibited in a healthy population of children (8-11 years) and adolescents (12-17 years), ${ }^{6}$ whereas Boerner et al's meta-analysis notes several effects of age and sex in children, highlighting that even in pediatric populations, developmental differences must be considered. ${ }^{7}$

The recent decade has seen a surge of studies of CPM in children and adolescents making it critical to produce an update of the current state of research to provide indications for future studies and research directions. This review focuses on 12 studies published between 2008 and 2017 dealing with CPM in pediatrics in different age groups (7-19 years). We discuss the demographics, methodology, and variability in results in CPM assessment and give recommendations for prospective studies that aim to further promote individualized treatment of pediatric pain syndromes.

\section{Materials and methods}

In order to provide an overview of current studies and advancements in CPM in clinical pediatric populations, a literature search in PubMed was performed using combinations of the following terms: "DNIC" ("Diffuse Noxious Inhibitory Controls"), "CPM" ("Conditioned Pain Modulation"), "Clinical," "Pediatric," "Pain," and "Chronic Pain." One of the first studies examining CPM in a solely pediatric population was by Goffaux et $\mathrm{al}^{8}$ in 2008 and was therefore used as the starting point for this review. Since this review aimed to examine the current literature regarding CPM in pediatric populations, abstracts of the search results were reviewed, and 12 studies that primarily investigated CPM in a solely pediatric population were identified. Studies that had a CPM component but did not measure CPM change as an endpoint were excluded. The aim of these inclusion and exclusion criteria was to provide better context on current clinical population selection, methodology, reporting of results and outcomes, and clinical significance of CPM in non-adult populations. Four studies included in this review examined children who were either healthy or not suffering from a pain syndrome. ${ }^{6,9-11}$ These are also discussed to provide a more broad overview of considerations in use of CPM with respect to experimental methodology and demographic selection when studying and managing pediatric pain.

\section{Results}

A summary of study characteristics as well as some results of those studies identified in this review are included in Table 1. Terminology was standardized among the various testing modalities and studies (eg, all tests involving application of a thermode irrespective of size were abbreviated to "thermode") to allow for better comparability among studies. Two studies in healthy children examined the effects of age stratification and race on CPM, respectively. ${ }^{6,9}$ It is important to note that these studies used different test stimuli to elicit pain in the participant as well as different conditioning stimuli among each other. The other 10 studies in clinical populations reviewed in this article also showed a remarkable variability with respect to the way CPM was conducted, reflecting the lack of a common consensus in CPM methodology. Specifically, the variability is found in the type of CS and TS used, as well as the sites to which the CS and TS are applied, and the duration of CS.

\section{Demographics}

Among the studies reviewed, age of the participants ranged from 7 to 19 years, involving a broad range of clinical conditions including musculoskeletal (MSK) pain, chronic pain (headaches, myofascial, neurovisceral, fibromyalgia, and joint pain), irritable bowel syndrome (IBS), obesity, and traumatic experiences in the neonatal intensive care unit (NICU) resulting from preterm birth (Table 1). The difference in CPM effect as a child ages is well-documented in the study by Tsao et $a l ;{ }^{6}$ however, it is interesting to note that of the 9 studies ${ }^{5,6,9-15}$ in which there are participants who are both above and below the age of 13 years (to differentiate between children and adolescents), only one such study mentions this age effect in its discussion. ${ }^{15}$ Only one study focused solely on girls rather than both boys and girls, but it should be noted that none of the studies found any differences in CPM due to sex, and only indirect effects from separating the study population by race. ${ }^{9}$

\section{CPM methodology}

About half of the studies reviewed here (Table 1) used variations of pressure pain thresholds (PPTs) via a pressure algometer as their TS, whereas the remaining studies used the application of heat as their TS. Nearly all studies examined in this review used a cold pressor task (CPT) as their CS, although the temperature of the water bath varied from $1^{\circ} \mathrm{C}$ to $13^{\circ} \mathrm{C}$ and the time of exposure to cold water lasted from 20 seconds to 3 minutes. A recent review of different pain 
Table I CPM study characteristics in pediatric populations

\begin{tabular}{|c|c|c|c|c|c|c|c|}
\hline Study & $\begin{array}{l}\text { Number of } \\
\text { participants }\end{array}$ & $\begin{array}{l}\text { Age } \\
\text { (years) }\end{array}$ & $\begin{array}{l}\text { Clinical } \\
\text { condition }\end{array}$ & $\begin{array}{l}\text { TS } \\
\text { (location) }\end{array}$ & $\begin{array}{l}\text { CS } \\
\text { (location) }\end{array}$ & $\begin{array}{l}\text { CPM } \\
\text { measurement }\end{array}$ & Results \\
\hline $\begin{array}{l}\text { Goffaux } \\
\text { et a }\left.\right|^{8}\end{array}$ & $\begin{array}{l}\text { I3 Pre-term } \\
\text { I3 Normal term }\end{array}$ & $7-11$ & $\begin{array}{l}\text { Pre-term } \\
\text { delivery and } \\
\text { resulting time } \\
\text { spent in NICU }\end{array}$ & $\begin{array}{l}\text { Thermode } \\
\text { (left forearm, } \\
\text { left calf) }\end{array}$ & $\begin{array}{l}\mathrm{CPT}, 13^{\circ} \mathrm{C} \text { for } 3 \\
\text { minutes total } \\
\text { (right hand) }\end{array}$ & $\begin{array}{l}\text { Difference in pain } \\
\text { ratings }\end{array}$ & $\begin{array}{l}\text { Early painful experiences } \\
\text { more strongly alter pain } \\
\text { processing, resulting in } \\
\text { decreased or absent CPM } \\
\text { effect in children with high } \\
\text { pain preterm }\end{array}$ \\
\hline $\begin{array}{l}\text { Evans } \\
\text { et } \mathrm{al}^{12}\end{array}$ & $\begin{array}{l}\text { I33 patients + } \\
\text { their mothers }\end{array}$ & $8-17$ & Chronic pain & $\begin{array}{l}\text { Pressure } \\
\text { algometer (left } \\
\text { thumbnail) }\end{array}$ & $\begin{array}{l}\mathrm{CPT}, 5^{\circ} \mathrm{C} \text { for } 30 \\
\text { seconds total } \\
\text { (right hand) }\end{array}$ & $\begin{array}{l}\text { Difference in pain } \\
\text { ratings }\end{array}$ & $\begin{array}{l}\text { Greater maternal pain } \\
\text { anxiety is significantly related } \\
\text { to less CPM (ie, less pain } \\
\text { inhibition) in boys }\end{array}$ \\
\hline $\begin{array}{l}\text { Tsao } \\
\text { et al }\end{array}$ & $\begin{array}{l}44 \text { children }(8-11 \\
\text { years) } \\
80 \text { adolescents } \\
(12-17 \text { years })\end{array}$ & $8-17$ & $\begin{array}{l}\text { Healthy } \\
\text { children }\end{array}$ & $\begin{array}{l}\text { Pressure } \\
\text { algometer (left } \\
\text { thumbnail) }\end{array}$ & $\begin{array}{l}\mathrm{CPT}, 5^{\circ} \mathrm{C} \text { for } 30 \\
\text { seconds total } \\
\text { (right hand) }\end{array}$ & $\begin{array}{l}\text { Difference and } \\
\text { percent change in } \\
\text { pain ratings }\end{array}$ & $\begin{array}{l}\text { No sex interactions. CPM } \\
\text { effect demonstrated in all } \\
\text { groups, but more robust } \\
\text { effect in older adolescents } \\
\text { compared to children }\end{array}$ \\
\hline $\begin{array}{l}\text { Williams } \\
\text { et } \text { al }^{17}\end{array}$ & $\begin{array}{l}22 \text { IBS } \\
16 \text { healthy control }\end{array}$ & $7-12$ & IBS & $\begin{array}{l}\text { Thermode } \\
\text { (right forearm) }\end{array}$ & $\begin{array}{l}\mathrm{CPT}, 12^{\circ} \mathrm{C} \text { for I } \\
\text { minute total } \\
\text { (left hand) }\end{array}$ & $\begin{array}{l}\text { Difference in } \\
\text { pain detection } \\
\text { thresholds }\end{array}$ & $\begin{array}{l}\text { Reduction of CPM effect } \\
\text { both absolutely and } \\
\text { compared to controls }\end{array}$ \\
\hline $\begin{array}{l}\text { Morris } \\
\text { et } \mathrm{al}^{9}\end{array}$ & $\begin{array}{l}40 \text { African- } \\
\text { American } \\
38 \text { Non-Hispanic } \\
\text { White }\end{array}$ & $10-17$ & $\begin{array}{l}\text { Healthy } \\
\text { children }\end{array}$ & $\begin{array}{l}\text { Thermode } \\
\text { (non-dominant } \\
\text { forearm) }\end{array}$ & $\begin{array}{l}\text { Warm water bath } \\
\text { at } 46.5^{\circ} \mathrm{C} \text { for } 60 \\
\text { seconds } \\
\text { (dominant hand) }\end{array}$ & $\begin{array}{l}\text { Difference in pain } \\
\text { ratings }\end{array}$ & $\begin{array}{l}\text { African-Americans reported } \\
\text { lower CPM effects than non- } \\
\text { Hispanic White children }\end{array}$ \\
\hline $\begin{array}{l}\text { Evans } \\
\text { et } \mathrm{al}^{13}\end{array}$ & 80 patients & $8-18$ & Chronic pain & $\begin{array}{l}\text { Pressure } \\
\text { algometer (left } \\
\text { thumbnail) }\end{array}$ & $\begin{array}{l}\mathrm{CPT}, 5^{\circ} \mathrm{C} \text { for } 30 \\
\text { seconds total } \\
\text { (right hand) }\end{array}$ & $\begin{array}{l}\text { Difference in pain } \\
\text { ratings }\end{array}$ & $\begin{array}{l}\text { Maternal anxiety is } \\
\text { significantly related to CPM } \\
\text { results }\end{array}$ \\
\hline $\begin{array}{l}\text { Morris } \\
\text { et al }{ }^{14}\end{array}$ & $\begin{array}{l}63 \text { FAP } \\
77 \text { healthy control }\end{array}$ & $10-17$ & $\begin{array}{l}\text { Functional } \\
\text { abdominal } \\
\text { pain }\end{array}$ & $\begin{array}{l}\text { Thermode } \\
\text { (non-dominant } \\
\text { forearm) }\end{array}$ & $\begin{array}{l}\text { Warm water bath } \\
\text { at } 46.5^{\circ} \mathrm{C} \text { for } 60 \\
\text { seconds } \\
\text { (dominant hand) }\end{array}$ & $\begin{array}{l}\text { Difference in pain } \\
\text { ratings }\end{array}$ & $\begin{array}{l}\text { Impaired CPM in youth with } \\
\text { FAP compared to healthy } \\
\text { controls }\end{array}$ \\
\hline $\begin{array}{l}\text { Rathleff } \\
\text { et al }{ }^{18}\end{array}$ & $\begin{array}{l}20 \text { patients } \\
\text { (current PFP) } \\
20 \text { control (no } \\
\text { current pain) }\end{array}$ & $15-19$ & MSK pain & $\begin{array}{l}\text { Cuff pressure } \\
\text { algometer } \\
\text { (lower leg on } \\
\text { painful side) }\end{array}$ & $\begin{array}{l}\text { Pressure cuff- } \\
\text { induced pain } \\
\text { (left bicep) }\end{array}$ & $\begin{array}{l}\text { Percentage change } \\
\text { in pain detection } \\
\text { and pain tolerance } \\
\text { thresholds }\end{array}$ & $\begin{array}{l}\text { Significant reduction in both } \\
\text { detection and tolerance } \\
\text { thresholds in patients with } \\
\text { current pain vs controls }\end{array}$ \\
\hline $\begin{array}{l}\text { Stolzman } \\
\text { and } \\
\text { Hoeger } \\
\text { Bement }{ }^{\prime \prime}\end{array}$ & $\begin{array}{l}32 \text { patients } \\
\text { (overweight) } \\
24 \text { controls } \\
\text { (normal weight) }\end{array}$ & $12-18$ & $\begin{array}{l}\text { Excess weight } \\
\text { / obesity }\end{array}$ & $\begin{array}{l}\text { Pressure } \\
\text { algometer (left } \\
\text { deltoid and } \\
\text { nailbed on 4th } \\
\text { digit) }\end{array}$ & $\begin{array}{l}\text { Ice bath, } 1^{\circ} \mathrm{C} \\
-2^{\circ} \mathrm{C} 20 \text { seconds } \\
\text { (right foot) }\end{array}$ & $\begin{array}{l}\text { Difference in } \\
\text { pain detection } \\
\text { thresholds }\end{array}$ & $\begin{array}{l}\text { No significant difference in } \\
\text { CPM among groups. Left } \\
\text { arm lean mass positively } \\
\text { associated to increasing CPM } \\
\text { effect }\end{array}$ \\
\hline $\begin{array}{l}\text { Stolzman } \\
\text { and } \\
\text { Bement }^{10}\end{array}$ & $\begin{array}{l}55 \text { patients } \\
\text { (unclear } \\
\text { separation into } \\
\text { low, moderate and } \\
\text { high pain groups) }\end{array}$ & $12-18$ & $\begin{array}{l}\text { Pain during } \\
\text { exercise } \\
\text { testing }\end{array}$ & $\begin{array}{l}\text { Pressure } \\
\text { algometer (left } \\
\text { deltoid and } \\
\text { nailbed on 4th } \\
\text { digit) }\end{array}$ & $\begin{array}{l}\text { Ice bath, } I^{\circ} \mathrm{C} \\
-2^{\circ} \mathrm{C} 20 \text { seconds } \\
\text { (right foot) }\end{array}$ & $\begin{array}{l}\text { Difference in } \\
\text { pain detection } \\
\text { thresholds }\end{array}$ & $\begin{array}{l}\text { CPM showed small positive } \\
\text { correlation with exercise- } \\
\text { induced hypoalgesia. Authors } \\
\text { postulate CPM having an } \\
\text { additive effect on ElH }\end{array}$ \\
\hline $\begin{array}{l}\text { Holley } \\
\text { et } \mathrm{al}^{5}\end{array}$ & $\begin{array}{l}88 \text { patients with } \\
\text { acute pain }\end{array}$ & $10-17$ & MSK pain & $\begin{array}{l}\text { Thermode } \\
\text { (dominant } \\
\text { forearm) }\end{array}$ & $\begin{array}{l}\mathrm{CPT}, 8^{\circ} \mathrm{C} \text { for I } \\
\text { minute total } \\
\text { (non-dominant } \\
\text { hand) }\end{array}$ & $\begin{array}{l}\text { Ratio of pain } \\
\text { tolerance } \\
\text { thresholds }\end{array}$ & $\begin{array}{l}\text { Poor CPM is predictive of } \\
\text { persistent pain and pain- } \\
\text { related disability at 4-month } \\
\text { follow-up }\end{array}$ \\
\hline $\begin{array}{l}\text { Holley } \\
\text { et al }{ }^{15}\end{array}$ & $\begin{array}{l}69 \text { acute pain } \\
62 \text { chronic pain } \\
60 \text { control with } \\
\text { no chronic pain }\end{array}$ & $10-17$ & MSK pain & $\begin{array}{l}\text { Thermode } \\
\text { (dominant } \\
\text { forearm) }\end{array}$ & $\begin{array}{l}\mathrm{CPT}, 8^{\circ} \mathrm{C} \text { for } 20 \\
\text { seconds total } \\
\text { (non-dominant } \\
\text { hand) }\end{array}$ & $\begin{array}{l}\text { Ratio of pain } \\
\text { tolerance } \\
\text { thresholds }\end{array}$ & $\begin{array}{l}\text { No significant differences in } \\
\text { CPM among groups. Authors } \\
\text { comment on age effects and } \\
\text { consider separating groups } \\
\text { by teenage vs childhood } \\
\text { years. Pain anxiety and } \\
\text { catastrophizing are predictive } \\
\text { of greater pain morbidity and } \\
\text { pain sensitivity, respectively }\end{array}$ \\
\hline
\end{tabular}

Abbreviations: CPM, conditioned pain modulation; TS, test stimulus; CS, conditioning stimulus; NICU, neonatal intensive care unit; CPT, cold pressor task; pain rating, based on self-reported score; IBS, Irritable bowel syndrome; FAP, functional abdominal pain; PFP, patellofemoral pain; MSK pain, musculoskeletal pain; EIH, exercise-induced hypoalgesia. 
modalities further confirms this wide variability in use of the CPT in several studies, which further reinforces a need for standard protocols for each method of inducing pain whether it be as a test or CS. ${ }^{16}$ The review further implies the need for standardization of other stimuli used in these studies including the heat pain via thermode and pressure pain. It seems that there is consensus in using pressure and heat pain as test stimuli and a cold water bath as a CS to elicit CPM effects.

\section{CPM effects}

Most of the studies reviewed in this publication showed decreased CPM effect in the clinical population compared to their control population, further confirming the paradigm of reduced pain inhibition in idiopathic pain patients. ${ }^{3}$ Although Stolzman and Hoeger Bement did not note any reduced CPM effects, there was still a correlation with left arm lean mass in a study on patients differentiated by weight ${ }^{11}$ and having an additive effect on exercise-induced hypoalgesia. ${ }^{10}$ However, it should be noted that rather than clinical populations with known pain syndromes, the study participants were otherwise healthy children and adolescents who had either normal or elevated BMI. ${ }^{10,11}$ Therefore, these results do not detract from conclusions drawn by other studies. In a longitudinal study conducted by Holley et al on patients with acute pain, they noted that poor CPM as well as depressive symptoms were predictive of persistent pain and pain-related disability. ${ }^{5}$ In addition, in another clinical control trial, they noted that although there were no differences in CPM, pain anxiety and catastrophizing were predictive of greater pain morbidity and pain task sensitivity, respectively. ${ }^{15}$ This finding relates to the earlier results by Evans et al that maternal anxiety is related to a reduction in CPM effect, introducing the consideration of controlling for psychosocial variables while testing CPM. ${ }^{12,13}$

\section{Discussion}

\section{Role of the descending pain inhibitory system on the development of chronic pain}

One of the first studies whose aim was to associate the exposure to painful experiences early in life with an alteration of descending inhibitory systems later in childhood was conducted by Goffaux et al. ${ }^{8}$ The research group compared term-born children with low-pain and high-pain preterm children and found that high-pain preterm children exhibited the lowest inhibitory responses. This result obtained by a longitudinal approach suggests that neuronal plasticity present during infancy can be affected by trauma, and hence shape the development and maturation of descending pain inhibitory systems. ${ }^{8}$ Meanwhile, Williams et al concluded that the absence of endogenous pain inhibition may either develop early in the onset of chronic and painful illnesses such as IBS and that due to deficient endogenous pain inhibition stemming from painful experiences during infancy, youth may be at a greater risk to develop IBS. ${ }^{17}$ Both of these studies confirm previous research done in adult populations, where those exposed to painful conditions consistently had a deficient functioning of descending inhibitory pathways compared to healthy controls (see Yarnitsky for an exhaustive review ${ }^{3}$ ). While both Goffaux et $\mathrm{al}^{8}$ and Williams et al ${ }^{17}$ have proposed that pain inhibitory pathways are affected by frequent and early exposure to painful experiences, it is not yet conclusive if this exposure is predictive of the onset and severity of chronic pain later in life. However, the studies by Morris et $\mathrm{al}^{14}$ and Rathleff et $\mathrm{al}^{18}$ indicate that this effect is not solely limited to early life exposures and that the presence of MSK pain or functional abdominal pain may also alter the descending pain inhibitory pathways. A recent study by Holley et al did not identify the differences in inhibitory pain pathways among children with MSK pain compared to pain-free children. ${ }^{15}$ This study benefited from a larger sample size compared to other previous studies, and as well had similar CPM testing conditions compared to several of the other included studies..$^{5,8,17}$. However, the CS lasted only 20 seconds in this study, compared to times ranging from 1 to 3 minutes in the other studies with comparable methodology. This short duration may not have been long enough to activate or produce a CPM effect. ${ }^{19}$ In addition, the study had broad inclusion criteria for MSK pain, including children with limb, back, or neck pain. Meanwhile, the study by Williams et $a{ }^{17}$ restricted the pain conditions to girls with IBS, the study by Goffaux et $\mathrm{al}^{8}$ included only premature infants who stayed in the NICU as their pain condition of interest, and Morris et al restricted their inclusion criteria to functional abdominal pain. ${ }^{14}$ In terms of MSK pain, Rathleff et al restricted their study condition to patellofemoral pain exclusively. ${ }^{18}$ Restricting the pain conditions could eliminate possible CPM effect variability brought upon by the inclusion of various pain conditions.

\section{CPM assessment - various approaches}

The 12 studies reviewed in this article show a variability with respect to the way CPM is tested, reflecting the lack of a common consensus in CPM methodology comparable to the one observed in adult studies. ${ }^{3,20}$ The variability in the implementation of CPM derives from different modalities 
used for the CS and TS as well as from the duration in which the different stimuli are administered ${ }^{16}$. Although in most of the studies, the application of CS and TS temporarily overlaps, ${ }^{5,6,10-13,15,17,18}$ some studies use an approach in which CS and TS are assessed successively. ${ }^{8,9,14}$ About half of the studies reviewed here (Table 1) used variations of PPTs as their TS, whereas the remaining studies included the application of heat as their TS. According to a study by Nahman-Averbuch et al, which aimed to compare different CPM effects derived from different CS/TS combinations, the application of pressure pain evokes stronger inhibitory responses compared to a thermal paradigm. ${ }^{20}$ Interestingly, their analyses targeting an adult population revealed weak correlations for different CPM paradigms assessed within the same sample. The authors conclude that the observed intermodality variability could be explained by the fact that different types of stimulations may activate different underlying pain pathways and that interpersonal predispositions (such as genetic influences or psychological factors) might have a varying impact on the perception of different types of pain..$^{20}$ As seen in studies by Evans et al and Holley et al, the effects of catastrophizing, anxiety, and parental influence on CPM and the experience of pain cannot be overlooked. . $^{12,13,15}$ This observation has led to the recommendation of using more than one paradigm in the experimental setting. ${ }^{20}$

Most of the studies chose cold water as their CS, which has been associated with the smallest variability in a testretest paradigm in adults. ${ }^{21}$ However, the temperature of the cold water bath varied from $1^{\circ} \mathrm{C}$ to $13^{\circ} \mathrm{C}$, and the exposure to cold water lasted from 20 seconds to 3 minutes. The duration of exposure as well as the temperature of the water can significantly impact the perception of pain when considering a $12^{\circ} \mathrm{C}$ range and ninefold increase in exposure time which makes the comparison of outcomes derived by different studies very difficult.

Not all the reviewed studies report the participants' perceived painfulness of the CS or control for it in their analyses. However, the CPM test paradigm requires the application of an often painful stimulus (CS) in order to modulate the TS, which cannot be ascertained and consequently compared to other studies if it is not reported. Therefore, CPM protocols should include the measurement of CS pain ratings prior to and during the CPM procedure. Also, there was a considerable variation in the site and type of result reported by the studies. For ease of interpretation, the measurement of patients' pain was referred to as their pain threshold. However, several studies measured the patients' response at "moderate pain intensity," their pain detection threshold, and/or their pain tolerance threshold. Even though a certain similarity and comparability exist, variation in the calculation of CPM efficacy, CPM index scores, or CPM magnitudes does not allow for results reported to be directly compared. Although some studies used the absolute difference between pain ratings before and after the CS (via either a numerical rating score or the temperature at which a stimulus was felt), ${ }^{8-12,14,17}$ other studies used a percent change or ratio $\left[(\text { post CPM - pre CPM)/pre CPM }]^{*} 100,{ }^{5,15,18}\right.$ and some others used both the absolute difference and percent change ${ }^{6,13}$ in accordance with the recommendations by Yarnitsky et al. ${ }^{22}$

Only two studies ${ }^{10,11}$ included a control condition in their protocol, making it possible to control for potential distraction or habituation effects. According to Yarnitsky et al, ${ }^{22}$ the second presentation of the TS shortly after the application of the CS as opposed to a simultaneous presentation of both TS and CS could furthermore reduce the effects of distraction. The inclusion of control conditions and an intraindividual variation of TS/CS combinations in further research can help to ensure both reliability and construct validity.

Lastly, the results of Tsao et al provide evidence for the need to separate patients by age groups, relating to their development and consequently the development of their descending inhibitory pain systems, ${ }^{6}$ further supported by a meta-analysis by Boerner et al on the effects of sex and age on pain perception. ${ }^{7}$. This should remain a consideration in both the design and the study of clinical pain, as well as in the diagnosis and management of pain syndromes by clinicians.

Finding ways for more robust measurement of effect and standardization of CPM protocols (while maintaining a certain clinical feasibility) remains a challenge for future studies.

\section{Conclusion and future directions}

This review aimed to provide researchers and clinicians in pediatrics with a brief, non-exhaustive overview of recent studies involving CPM in children with the aim to inform future studies and emphasize the need to consider impaired CPM as well as other psychosocial variables that play a role in the pain experienced in many pediatric pain patients.

The observed methodological variability makes it difficult to directly compare the different conclusions drawn from the different studies. Similar to suggestions in adult pain research, the use of different CS/TS combinations in the same study could help to elucidate the exact nature of underlying pain pathways in certain pain processes. ${ }^{21-23}$ As different types of stimulation (eg, thermal pain vs pressure pain) may result in different psychological and neurophysiological responses between individuals, CPM assessments 
should be accompanied by other measures to add further insight into the large variability observed in CPM efficacy and to aid in controlling other factors that may be heightening or dampening patients' pain, such as pain anxiety levels. ${ }^{21}$ Even though CPM has the potential to quantify pain mechanisms by experimentally manipulating a pain response, it uses subjective pain reports as an outcome measure and thus relies on the individual's ability to perceive, judge, and report pain. Especially when dealing with a young population, this might vary due to interindividual developmental differences. Other factors that modulate the complex perception of pain, such as psychosocial factors or genetic and molecular correlates should be taken into account when interpreting the obtained CPM results in a clinical context and can be added to research designs in an attempt to further enhance construct validity.

\section{Acknowledgment}

This research was funded by the Louise and Alan Edwards Foundation and the Montreal Children's Foundation (CE Ferland).

\section{Disclosure}

The authors report no conflicts of interest in this work..

\section{References}

1. Le Bars D, Dickenson AH, Besson JM. Diffuse noxious inhibitory controls (DNIC). I. Effects on dorsal horn convergent neurones in the rat. Pain. 1979;6(3):283-304.

2. Nir R-RR, Yarnitsky D. Conditioned pain modulation. Curr Opin Support Palliat Care. 2015;9(2):131-137.

3. Yarnitsky D. Conditioned pain modulation (the diffuse noxious inhibitory control-like effect): its relevance for acute and chronic pain states. Curr Opin Anaesthesiol. 2010;23(5):611-615.

4. Nahman-Averbuch H, Nir R-RR, Sprecher E, Yarnitsky D. Psychological factors and conditioned pain modulation: a meta-analysis. Clin J Pain. 2016;32(6):541-554.

5. Holley AL, Wilson AC, Palermo TM. Predictors of the transition from acute to persistent musculoskeletal pain in children and adolescents: a prospective study. Pain. 2017;158(5):794-801.

6. Tsao JC, Seidman LC, Evans S, Lung KC, Zeltzer LK, Naliboff BD. Conditioned pain modulation in children and adolescents: effects of sex and age. J Pain. 2013;14(6):558-567.
7. Boerner KE, Birnie KA, Caes L, Schinkel M, Chambers CT. Sex differences in experimental pain among healthy children: a systematic review and meta-analysis. Pain. 2014;155(5):983-993.

8. Goffaux P, Lafrenaye S, Morin M, Patural H, Demers G, Marchand S. Preterm births: can neonatal pain alter the development of endogenous gating systems? Eur J Pain. 2008;12(7):945-951.

9. Morris MC, Walker L, Bruehl S, Hellman N, Sherman AL, Rao U. Race effects on conditioned pain modulation in youth. J Pain. 2015;16(9): 873-880.

10. Stolzman S, Bement M. Does exercise decrease pain via conditioned pain modulation in adolescents? Pediatric Phys Ther. 2016;28(4):470-473.

11. Stolzman S, Hoeger Bement M. Lean mass predicts conditioned pain modulation in adolescents across weight status. Eur J Pain. 2016;20(6):967-976.

12. Evans S, Seidman LC, Lung KC, Zeltzer LK, Tsao JC. Sex differences in the relationship between maternal fear of pain and children's conditioned pain modulation. J Pain Res. 2013;6:231-238.

13. Evans S, Payne LA, Seidman L, Lung K, Zeltzer L, Tsao JC. Maternal anxiety and children's laboratory pain: the mediating role of solicitousness. Children (Basel). 2016;3(2):10.

14. Morris MC, Walker LS, Bruehl S, Stone AL, Mielock AS, Rao U. Impaired conditioned pain modulation in youth with functional abdominal pain. Pain. 2016;157(10):2375-2381.

15. Holley AL, Wilson A, Cho E, Palermo T. Clinical phenotyping of youth with new-onset musculoskeletal pain: a controlled cohort study. Clin J Pain. 2017;33(1):28.

16. Birnie KA, Caes L, Wilson AC, Williams SE, Chambers CT. A practical guide and perspectives on the use of experimental pain modalities with children and adolescents. Pain Manag. 2014;4(2):97-111.

17. Williams AE, Heitkemper M, Self MM, Czyzewski DI, Shulman RJ. Endogenous inhibition of somatic pain is impaired in girls with irritable bowel syndrome compared with healthy girls. J Pain. 2013;14(9):921-930.

18. Rathleff MS, Petersen KK, Arendt-Nielsen L, Thorborg K, GravenNielsen T. Impaired conditioned pain modulation in young female adults with long-standing patellofemoral pain: a single blinded cross-sectional study. Pain Med. 2016;17(5):980-988.

19. Kennedy D, Kemp H, Ridout D, Yarnitsky D, Rice A. Reliability of conditioned pain modulation. PAIN. 2016;157(11):2410-2419.

20. Nahman-Averbuch H, Yarnitsky D, Granovsky Y, Gerber E, Dagul P, Granot M. The role of stimulation parameters on the conditioned pain modulation response. Scand J Pain. 2013;4(1):10-14.

21. Oono Y, Nie H, Matos R, Wang K, Arendt-Nielsen L. The inter- and intra-individual variance in descending pain modulation evoked by different conditioning stimuli in healthy men. Scand J Pain. 2011;2(4): 162-169.

22. Yarnitsky D, Bouhassira D, Drewes AM, et al. Recommendations on practice of conditioned pain modulation (CPM) testing. Eur J Pain. 2015;19(6):805-806.

23. Klyne D, Schmid A, Moseley L, Sterling M, Hodges P. Effect of types and anatomic arrangement of painful stimuli on conditioned pain modulation. J Pain. 2015;16(2):176-185.
Journal of Pain Research

\section{Publish your work in this journal}

The Journal of Pain Research is an international, peer reviewed, open access, online journal that welcomes laboratory and clinical findings in the fields of pain research and the prevention and management of pain. Original research, reviews, symposium reports, hypothesis formation and commentaries are all considered for publication.

\section{Dovepress}

The manuscript management system is completely online and includes a very quick and fair peer-review system, which is all easy to use. Visit http://www.dovepress.com/testimonials.php to read real quotes from published authors. 